\title{
JOGOS MATEMÁTICOS COMO MÉTODOLOGIA E MECANISMO PARA APRENDIZAGEM MATEMÁTICA
}

\author{
Bruno da Silva Santos \\ Orientador(a): Flávia Carneiro Santos Morais
}

\section{Resumo}

Diante as necessidades de modificação e melhoria na metodologia de ensino da matemática, em prol de despertar o interesse dos alunos com relação ao estudo e aprendizagem e desmistificar a ideia de que a disciplina é difícil, ressaltando entre eles a dificuldade no aprendizado, foi elaborado o presente trabalho apresentando a importância dos jogos matemáticos no ensino fundamental II com estratégia de melhoria da prática educativa em sala de aula, quebrando o paradigma de dificuldade da disciplina, podendo inibir os bloqueios no aprendizado dos alunos. Nesse contexto responder a interrogativa da necessidade de modernização e melhorias no ensino da matemática buscando mecanismos que estimule um aprendizado dinâmico e atrativo, preparando o aluno para resolver os desafios propostos pelas necessidades do cotidiano, desenvolvendo uma inteligência prática nas resoluções de problemas e tomadas de decisões, habilitando uma ampla capacidade para tratar as atividades matemáticas. E até que ponto os jogos dentro da didática tem sua contribuição significadora para o ensino e aprendizado no contexto escolar como metodologia, estimulando a utilização de estratégias, o raciocínio logico e a comunicação dentro do mesmo espaço.

Palavras-chave: Metodologia. Aprendizagem. Jogos matemáticos.

\section{INTRODUÇÃO}

A prática de ensino nos últimos tempos passa por grandes mudanças, apresentando evoluções nas metodologias aplicadas, e o professor como papel de mediador, busca acompanhar esse avanço buscando recursos para aprimorar sua didática, acrescentando novos mecanismos e atividades para que estimule a participação dos alunos dentro da sala de aula. Para Alves (2006) recursos didáticos são atividades materializadas, criadas pelo professor quando sente a necessidade de intervenção para reforçar o aprendizado dos alunos. O aluno já inicia seus estudos em relação a matemática com certos traumas formados a partir de culturas e bases familiares que terminam prejudicando e aprendizagem da matemática, em sua maioria são maledicentes em relação a disciplina. "A relação que caracteriza o ensinar e o aprender transcorre a partir de vínculos entre as pessoas e inicia-se no âmbito familiar" (TASSONI, 2000). Com esse desafio, o professor é levado a usar de sua criatividade e descobrir meios que aproxime das necessidades da turma, a fim de entender o assunto trabalhado, incluindo a 
utilização de materiais manipuláveis e recursos que melhore a comunicação, facilitando o entendimento das informações.

Existe a necessidade de compreensão por todos envolvidos no ambiente escolar, principalmente por alunos e professores, ressaltando que a matemática é essencial para o desenvolvimento da sociedade, pela necessidade na formação do cidadão em saber contar e interpretar questões matemática em situações práticas e cotidianas no seu dia a dia é interessante o acesso a informações que permita que os estudantes, professores e profissionais escolares compreendam a essência da matemática para o desenvolvimento da sociedade.

O principal ponto que desafia o professor de matemática é demonstrar através da aplicabilidade de jogos e materiais palpáveis ou virtuais, quebrando toda a interpretação de que é uma disciplina árida, abstrata, de quadro e giz, e de difícil aprendizagem, levantando a sua importância para o conhecimento cientifico, que é essencial, e vão além das necessidades para as atividades da disciplina, mais conhecimentos de outras áreas também. Nesse sentido é que realiza um exercício de crescimento humano no qual a educação se constitui em um princípio gerador, fomentador e sustentáculo na formação de um novo ser (MENDES, 2009, p.14).

Precisa levantar a exultação no que se diz respeito ao estudo da matemática, onde os levantem as expectativas e participem das atividades propostas, resolvendo problemas com operações matemáticas, sem duvidas e nem dificuldade, tornando interessante a presença nas aulas e que os jogos sejam um estimulador para resolver as operações matemáticas, com o objetivo de formar pessoas, contribuindo para alcançar patamares mais elevados. "Deve-se priorizar o aluno como sujeito da aprendizagem e estimulá-lo a compreender conceitos e técnicas matemáticas" (LONDERO, 2009, p.29). Quando se fala em operações matemáticas, coloca-se em questão a base para o entrosamento do aluno com a disciplina, pois, se existe deficiência na execução de operações de soma, subtração, multiplicação e divisão, existirá sempre um distanciamento entre o receptor e os assuntos que constitui a grade curricular de ensino básico voltado para a matemática.

Muitos estudiosos da área de Educação Matemática têm desenvolvido pesquisas sobre a importância dos jogos no processo ensino aprendizagem da Matemática e afirmam sobre a importância deste recurso como metodologia na sala de aula. "Essa perspectiva está baseada no fato de que os jogos, e o processo dinâmico que eles promovem, favorecem a construção e a socialização do conhecimento" (LONDERO, 2009, p. 37).

É com esse intuito que os jogos matemáticos auxiliam o professor e através das atividades lúdicas e os desafios de competição em conjunto com a aprendizagem desperta o 
interesse para participar e o entendimento do assunto. Nesse contato com materiais concretos dentro dos novos modelos de ensino e aprendizagem da matemática que pode facilitar a aproximação do aluno com a disciplina, criando assim outro olhar em relação ao aprendizado, deixando claro que a necessidade de ensino da matemática não estar somente nos materiais em si, mais os jogos podem ser um apoio para nivelamento da classe como uma ligação resolutiva diante as situações particulares dos diversos contextos de aprendizagem. O objetivo é demonstrar o papel metodológico do jogo no processo de ensino e aprendizagem da matemática, levando em conta a relação, as concepções e a funções envolvidas na utilização dos jogos matemáticos e de que forma será um facilitador no entendimento para o estudo de função, sendo um proporcionador de interesses em participação dos alunos.

Nesse contexto, aborda-se dentro de uma escola publica municipal, numa turma de 6 ano do ensino fundamental II, qual o nível de conhecimento em relação a matemática, e quantos entre ele apresentam dificuldade no aprendizado, discutindo com o professor da disciplina sobre o modelo do ensino da matemática na turma, abordando causas e efeitos, levantando a ideia do avanço apresentado no ensino e aprendizagem da matemática e os novos modelos de didáticas, através de recursos e materiais modificadores, que auxiliam no entendimento, proporcionando a participação dos alunos nas aulas. Logo após o jogo é apresentado como uma possível proposta de redimensionamento para várias situações, destacando seus objetivos e seus valores pedagógicos, e por fim inferências e considerações finais.

\section{DESENVOLVIMENTO}

O modelo de ensino passa por grandes avanços, a humanidade cria outros conceitos de posicionamento e expectativas com relação aos alunos, e nesse ensejo o professor perde a configuração de passar informações, "sabe tudo", e que ele está na sala de aula apenas para o cientifico e incorpora o papel de intermediador, onde precisa conhecer seu aluno, entender o seu aluno e interpretar as diferenças na classe, para que com esse diagnostico constituído possa definir a sua postura e planejar suas atividades. "A pratica letiva que tenha em conta o conhecimento das representações sociais do professor melhorará de forma considerável o processo de ensino e de aprendizagem da matemática” (Graça etal., 2004, p. 39).

A educação exerce um papel importante na humanidade e todos os envolvidos significativamente tem a capacidade de contribuição, planejando, organizando e priorizando novas metodologias, dando prioridade a inovação do modelo de ensino com a criação de 
estratégias e argumentação, levando em conta a criatividade, para que se alcance o estimulo e participação dos alunos, com o objetivo de atender as expectativas das atividades propostas.

Para Londero (2009):

Para que a educação adquira essa competência toda, a comunidade escolar deve mostrar-se, deixar transparecer filosofia de vida e de pensamento. Seus agentes devem conduzir a libertação dos mecanismos que dificultam sua busca de conhecimento e de felicidade. Consciente de seus limites e procurando não absolutizar seus conhecimentos, mas produzi-los, podem assumir um posicionamento critico que lhes permitirá perceber que a formação do saber historicamente construído é elaborada através do acúmulo de experiências individuais e/ou coletivas.

Existe uma cultura na sociedade em que muitos afirmam que a matemática é a disciplina difícil de entendimento e aprendizagem, esse paradigma é hereditariamente passados e terminam atingindo os alunos até hoje. Eles já chegam na sala de aula apresentando essa resistência em aprender matemática, pois passaram o tempo todo ouvindo dos seus familiares, vizinhos e até mesmo de muitos professores. Segundo Graça et al. (2004, p. 38, apud BENAVANTE, 1990, p. 92) relativamente aos professores, a representação que têm da sua profissão, da instituição em que trabalham e dos alunos, influenciará no modo de viver a profissão e as suas práticas em relação aos alunos. Essa situação cria um grande desafio para o professor em sala de aula, porque além, de passar os conteúdos pertencentes a grade curricular, tem papel importante de converter os conceitos dos alunos com relação a disciplina.

Conhecer as quatro operações matemáticas básicas é fundamental para o desenvolvimento do estudo dos alunos, onde fica contestado que o processo de ensino da matemática e as sequências de assuntos dados por série, apresentam dependências e/ou ligação entre eles, ou seja, o aluno não terá condições de avançar seus estudos na disciplina se não tiver o entendimento sobre a aplicabilidade da função. "Um conceito adquire significados por meio de uma variedade de situações, e diferentes aspectos de um mesmo conceito e operações estão envolvidas em diferentes situações" (CUNHA, 1997). Para Londero (2009, p.20) o uso de metodologia com a utilização de jogos e atividades lúdicas que posicionam os alunos como sujeito da aprendizagem, necessita de uma maior dedicação por parte do professor no planejamento e o acompanhamento das atividades. Cabe ao professor com o papel de mediador, buscar recursos para que as aulas se tornem mais atraente e participativa, implantando outro método de aprendizagem com a participação prática dos alunos e o envolvimento com a real razão de saber matemática, que tem se tornado elemento comum na 
base de formação educacional do indivíduo caracterizando-se como um campo de saber essencial. "Um recurso é um analogia que se usa para, através de comparação, conseguir que o aluno entenda os conceitos abordados pelo professor com a função de criar uma orientação no sentido de facilitar a aquisição de conhecimentos" (ALVES e MORAIS, 2006, p. 336).

Os jogos e as atividades ilustrativas estão presentes no dia a dia dos jovens desde a sua relação familiar, até mesmo o convívio na sociedade atual. Aproveitando as novas características e comportamentos desses jovens, a escola como ambiente de conhecimento vem adotando novas metodologias, adaptando os jogos como um mecanismo de ensino, para que se alcance a participação e aprendizado dos alunos. "A pretensão da maioria dos professores, com a sua utilização, é a de tornar as aulas mais agradáveis com o intuito de fazer com que a aprendizagem torne-se algo fascinante" (LARA, 2004, p.2).

Essas atividades podem ser um caminho estratégico para a estimulação do raciocínio, podendo compactuar na capacitação decisivas no seu cotidiano, e também uma caminho cientifico que pode assegurar a singularidade do conhecimento matemático, pois, o individuo capacita os assuntos abordados e socializa com a aplicação dos jogos, sendo esse corresponsável com a transformação. De acordo com Piaget (1998, apud Mota et al. 2009, p.25) "os jogos tornam-se mais significativos à medida que a criança se desenvolve, pois a partir da livre manipulação de situações variadas, ela passa a reconstruir objetos, reinventar as coisas".

Para Grübel e Bez (2006, p. 02):

Hoje em dia se encontram muitos jogos educativos e cabe ao educador selecionar e avaliar esses, buscando utilizá-los da melhor forma possível. Esses podem ser mais um dos agentes transformadores da educação, mas vai depender muito da forma como serão utilizados e explorados. Os educadores têm papel fundamental, pois é através do contexto, reflexão crítica e intervenções que os jogos educativos vão contribuir para o desenvolvimento dos educandos e a construção da aprendizagem.

É necessário o bom planejamento e controle por conta do professor, traçar objetivos a serem alcançados, o ambiente em que a atividade será aplicada e o tempo necessário para cada atividades, com informações e regras claras, e o monitoramento para que haja coerência no decorrer da prática. Muitos estudiosos afirmam que os jogos pode ser um vilão na constituição de características do aluno, tornando-o mais dispersos, sem a criação formal da responsabilidade, mesmo por que, apara esses, tudo será desenvolvido em forma de brincadeira. 


\subsection{Modelo de jogos}

A adequação de jogos nas salas de aula para o alcance dos objetivos da aprendizagem não é algo novo, pois já se reconhece sua valorização para o ensino e aprendizagem da matemática e outras áreas do conhecimento. No que se desrespeitam as aulas de números e problemas matemáticos, o uso dos jogos na sala de aula modifica o processo, quebrando as resistências de aprendizado de muitos alunos, deixando a aula mais divertida e satisfatória. Para Mota et. Al. (2009), “o jogo é visto como estando na origem do pensamento, da descoberta de si mesmo, da possibilidade de experimentar, de criar e de transformar o mundo, onde se apresenta o lúdico".

As atividades com jogos aplicadas numa turma de ensino fundamental II quando projetada, apresentando um bom planejamento e uma orientação descomplicada e acessível, pode desenvolver habilidades, principalmente relacionadas à observação, limites, reflexão, criação de hipóteses, desenvolvimento da linguagem, argumentação e organização e tomada de decisões, capacitando assim, o raciocínio lógico do indivíduo. Os jogos disponibiliza uma sensação de prazer e aprendizagem com significância para o ensino da matemática. Para Londero (2009, p.12) "os jogos é uma ajuda para viajar por mundos imaginários em alguns instantes e retomar à realidade na mesma intensidade de tempo".

No decorrer das atividades alguns empecimentos podem ocorrer decorrentes dos múltiplos níveis de conhecimento entre os alunos das turmas. Por se tratar das series finais do ensino fundamental II, são alunos transferidos de diversas escolas, localidades diferentes e variados professores e metodologias adotadas. E muitos com insegurança em assuntos bases, que direcionam a culpa para o professor, reclamando da sua didática. Foi nitidamente visível que a maioria dos profissionais da educação ainda resiste em passar determinados conteúdos aos seus alunos sem estar cautelosos aos objetivos científicos e permanecem a ensinar da forma que ele sabe, mesmo sem fundamentação. Com isso resolver operações matemáticas se torna uma ação repetitiva, sem que o aluno consiga interpretar a real razão do passo a passo dentro de cada operação. Isso traz uma dificuldade ano após ano, e a cada serie que o aluno avança.

Acompanhando o objetivo desse estudo, a utilização do jogo esta baseada a uma perspectiva de resolução de problemas e melhoria de entendimento e aprendizado dos assuntos abordados em sala, ou seja, os jogos matemáticos são colocados como uma atividade complementar permitindo uma forma de organizar o ensino, não somente melhorando a metodologia mais também inserir a concepção do que é ensinar e, consequentemente, sobre o que significa aprender. "A educação de modo geral, não tem sido orientada para o 
desenvolvimento de competências e habilidades nos alunos, mas sim para a tarefa de absorção de conteúdos" (LONDERO, 2009, p.13).

Existe uma grande variedade de jogos que podem ser adaptados para o ensino e aprendizagem da matemática, alguns deles serão demonstrado a seguir.

\section{1.1 Jogo da memória com as quatro operações}

O jogo da memória é um jogo prático e de fácil confecção, utiliza-se papelão, papel crepom e piloto permanente. Esse jogo é composto por 36 cartas de tamanhos 20 centímetros de largura por 15 centímetros de altura, 18 delas estarão a operação matemática e as outra 18 cartas seus respectivos resultados.

A turma deve ser dividida em duas equipes, e cada equipe deve ter dois representantes para movimentas as cartas que estarão posicionada no chão ao centro da sala. A equipe vencedora é aquela que encontrar a maior quantidade de operações e resultados correspondentes.

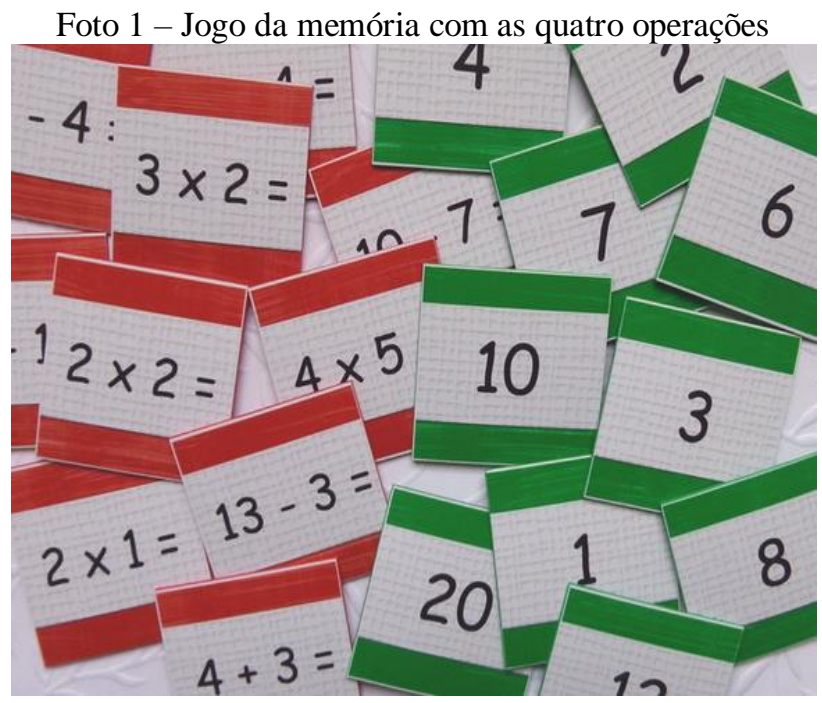

Fonte: https://www.elo7.com.br/jogo-da-memoria-matematica-nivel-2/dp/33B0D4, acesso em 02/01/2020 as 13:52 horas.

2. 1.2 Bingo das quatro operações

Um modelo de jogo individual, onde as fichas com as operações serão depositadas em uma urna e sorteadas uma de cada vez. O professor tira uma carta com a operação e escreve no quadro para os alunos, que deverão resolver numa folha de papel, depois que encontrar o resultado será marcado, pois estará em algumas cartelas. Vence o jogador que marcar todos os resultados contido na cartela. 


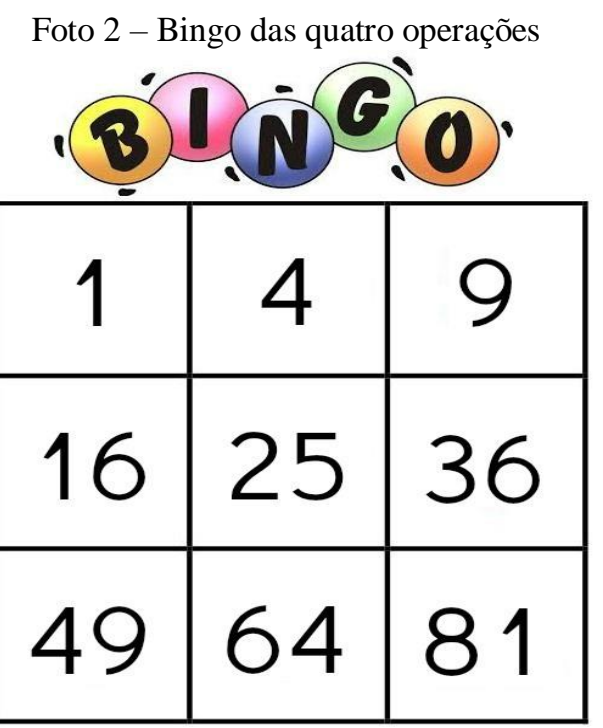

Fonte: https://oespacoeducar.com.br/wp-content/uploads/2019/05/Bingo-multiplicaciones-32.jpg, acesso em 02/01/2020 às 14:43 horas.

\section{CONSIDERAÇÕES FINAIS}

Em relação à aprendizagem matemática, pode-se afirmar que os jogos como metodologia permitem aos educandos desenvolvessem habilidades como atenção e raciocínio, propondo assim, uma correção em muitas das falhas de aprendizagem e também o conceito pessoal de cada indivíduo relacionado à disciplina e seus assuntos abordados, quebrando aquele paradigma de que o ensino da matemática deve se manter de forma metódica entre quadro e livro didático. Como afirma Baumgartel (2016) que os jogos podem ser aplicados com o intuito de entretenimento e socialização, mas também como consequência o desenvolvimento de habilidades e de conceitos, podendo ser complementado por MOTA (2009) "um jogo, para ser útil no processo educacional, deve promover situações interessantes e desafiadoras para resolução dos problemas".

É no desenrolar das jogadas e com a intervenção do professor que pode ser captado as dificuldades da turma e as dúvidas serem sanadas, é por isso que em muitos das atividades com jogos aplicadas é importante a intervenção do professor como mediador em todas as atividades para uma explicação previa do assunto explicado e a utilização do quadro para maiores esclarecimentos.

Ao final das atividades pode-se destacar que o contato dos alunos a cada jogo faz estudar sobre as relações entre as operações matemáticas, com o intuito de alcançar o objetivo do jogo. Os alunos ficam bastante cuidadosos, no que desrespeita a organização ao movimentar as peças do jogo e o cumprimento das quantidades de jogadas foram propostas ao ler a regra do jogo, interligando dentro da atividade o entendimento do assunto abordado em 
sala. Para o professor foi levantada as considerações de que os jogos podem ser utilizados na abordagem de diversos assuntos e serem adaptados, garantindo mais um ponto a favor da utilização destes recursos. Mesmo com o direcionamento geral para toda a turma é possível perceber que o professor deve manter estratégias que consiga fazer um nivelamento de conhecimentos dentro da classe, elevando os níveis da turma para que avance para as próximas séries. Nesse contexto, é através do conhecimento sobre as quatro operações que os alunos começam a perceber a importância de raciocinar de acordo com as situações que convivem na prática.

Por fim, a matemática tem se tornado elemento comum a base de formação educacional e na prática educativa o envolvimento dos professores com seus alunos trazem resultados positivos no rendimento escolar de ambas as partes, principalmente, quando envolve atividades práticas que favorece a interpretação, discussão, expressão e representação dos problemas.

\section{REFERÊNCIAS}

ALVES, Carla; MORAIS, Carlos. Recursos de apoio ao processo de ensino e aprendizagem da matemática. Sociedade Portuguesa de Ciências da Educação,São Paulo, 2006.

ARAÚJO, Jussara de Loiola. Uma Abordagem Sócio-Crítica da Modelagem Matemática: a perspectiva da educação matemática crítica. Alexandria: Revista de Educação em Ciência e Tecnologia, v. 2, n. 2, p. 55-68, 2009.

BAUMGARTEL, Priscila. O uso de jogos como metodologia de ensino da Matemática. XX Encontro Brasileiro de Estudantes de Pós-Graduação em Educação MatemáticaEbrapem. Anais... Curitiba, p. 1-8, 2016.

CUNHA, Maria Carolina Cascino da et al. As operações de multiplicação e divisão junto a alunos de $5^{\text {a }}$ e $7^{\text {a }}$ séries.São Paulo: PUC, 1997.

FIORENTINI, Dario et al. Umareflexão sobre o uso de materiais concretos e jogos no Ensino da Matemática. Boletim da SBEM-SP, v. 4, n. 7, 1990.

GRAÇA, Maria Margarida da Silva; MOREIRA, Marco Antonio; CABALLERO SAHELICES, MaríaConcesa. Representacoes sobre a Matemática, seu ensino e aprendizagem: um estudo exploratório. Investigações em ensino de ciências. Vol. 9, n. 1 (jan./abr. 2004), p. 37-93, 2004.

GRÜBEL, Joceline Mausolff; BEZ, Marta Rosecler. Jogos educativos. RENOTE-Revista Novas tecnologias na Educação, 2006, 4.2.

LARA, Isabel Cristina Machado de. Jogando com a Matemática de $5^{\mathrm{a}}$ a $8^{\mathrm{a}}$ série. 2004. 
LIMA, Elon Lages et al. A matemática do ensino médio. 2002.

LONDERO, Evandro Felin. Matemática Lúdica. Grupo Uniasselvi. Indaial, 2009.

MACEDO, Lino de; PETTY, Ana Lúcia Sícoli; PASSOS, Norimar Christe. Os jogos e o lúdico na aprendizagem escolar. Artmed Editora, 2009.

MENDES, Iran Abreu. Matemática e investigação em sala de aula. Editora Livraria da Física. São Paulo, 2009.

MIGUEL, Antonio; MIORIM, Maria Ângela. História na educação matemática: propostas e desafios. Autêntica, 2013.

MORAES, Silvia Pereira Gonzaga de et al. Avaliação do processo de ensino e aprendizagem em Matemática: contribuições da teoria histórico-cultural. Bolemamathematics Education Bulletin-boletim de Educacao Matematica, v. 22, n. 33, p. 97-116, 2009.

MOTA, Paula Cristina Costa Leite de, et al. Jogos no Ensino da Matemática. 2009. Master's Thesis.

TASSONI, Elvira Cristina Martins. Afetividade e aprendizagem: a relação professoraluno. Psicologia, análise e crítica da prática educacional. Campinas: ANPED, p. 1-17, 2000. 